\title{
Object recognition as a function of stimulus characteristics
}

\author{
WILLIAM A. BARNARD \\ University of Northern Colorado, Greeley, Colorado \\ and \\ MARSHALL BREEDING and HENRY A. CROSS \\ Colorado State University, Fort Collins, Colorado
}

\begin{abstract}
Twenty-five college students were tested for recognition memory of small common objects immediately after exposure and after a retention interval of 1 week. The objects were classified into three object types based upon a cluster analysis of rated stimulus characteristics. The results indicated that recognition performance was influenced by object type and retention interval. The importance of considering stimulus characteristics in theoretical explanations of memory for environmental detail was discussed.
\end{abstract}

Adaptation to a new or unfamiliar environment involves the processing of information extracted from physical components of that environment. Few studies have reported the nature of visual information retained from objects and scenes in real-world environments. Using schematic drawings of realistic scenes, J. M. Mandler and her colleagues (J. M. Mandler \& Johnson, 1977; J. M. Mandler \& Parker, 1976; J. M. Mandler \& Ritchey, 1977) have demonstrated the differential influence on memory of various types of information contained within a scene. These studies represent the initial development of a taxonomy for environmental information processing and support the contention that diversity in new environmental information contributes to fitting that new information into existing schemata, a process that serves to consolidate new information relative to past experience (Bartlett, 1932; Minsky, 1975; Piaget \& Inhelder, 1973), "The extent to which pictures fit those schemata should influence how well they are remembered and perhaps what types of information are remembered" (J. M. Mandler \& Parker, 1976, p. 39). According to J. M. Mandler's initial taxonomy, scene schemata comprise at least four types of information (J. M. Mandler \& Ritchey, 1977): (1) inventory information-specifying what objects a picture contains; (2) descriptive information-specifying the figurative detail of the objects in the inventory (what the object looks like); (3) spatial-location information-specifying the position of objects in the scene, as well as their relation to other objects; and (4) spatial-composition

The authors wish to express their appreciation to Ray Cooksey for assistance in the preparation of these data. Requests for reprints should be sent to William A. Barnard, Department of Psychology, University of Northern Colorado, Greeley, Colorado 80639. information-specifying areas of filled and empty space.

The present study attempted to identify specific characteristics of information contributing to recognition memory for environmental objects. The focus was on the first category of the J. M. Mandler and Ritchey (1977) taxonomy. The term "information," as used in the present investigation, refers to the evaluated stimulus characteristics of common three-dimensional objects. The evaluations were obtained in an initial object rating on the following stimulus dimensions: familiarity, complexity, utility, attractiveness, interest, and physical definition.

Evidence suggesting the potential contribution of these characteristics to recognition performance is limited to verbal-learning studies of word stimuli in which stimulus familiarity is considered to be of central importance (Juola, Fischler, Wood, \& Atkinson, 1971; Kintsch, 1967; G. Mandler, 1972; Underwood, 1971). Recognition of a word is seen as a familiarity decision. Although some models propose additional search processes (G. Mandler, 1972, 1980), the role of stimulus familiarity in recognition involves deciding whether a stimulus word was present in an earlier list. This is based upon its familiarity value as determined by frequency counts of occurrence in common language (e.g., Thorndike \& Lorge, 1944). A stimulus being present within the experimental situation provides a boost in familiarity value and allows an individual to discriminate unfamiliar target words from words not previously presented. Unfamiliar words that are included in list-recognition studies presumably become disproportionately more familiar than do unfamiliar words that are not presented in the learning lists and that are used as foils in the recognition tests (Klatsky, 1980). The anticipated superiority of recognition for unfamiliar words over familiar words is well documented and 
consistent (Shepard, 1967; Underwood \& Freund, 1970). Since the definition of familiarity used in the present study is analogous to that used in the verballearning literature, a similar recognition superiority was expected for objects rated as being less frequently encountered (low familiarity). If the other stimulus dimensions do not influence the recognition process, then recognition performance should correspond directly to the familiarity ratings.

Complexity, utility, attractiveness, interest, and definition were included as additional dimensions of possible importance in object-recognition memory. Such factors could influence memory for physical objects and alter the familiarity/recognition effect. Objects rated high on these dimensions and also high in familiarity might lead to better recognition than would objects rated low.

As J. M. Mandler has demonstrated, some specific information found in schematic drawings is lost after a 1-week retention interval. A similar loss could be expected to occur for information relative to specific objects. It was predicted that recognition performance would decline after the retention interval.

\section{METHOD}

\section{Subjects}

Sixty-three college students participated in the initial object rating, and 25 students were used in the recognition test proper. All students received credit toward a general psychology course requirement.

\section{Materials}

Subjective ratings of six stimulus characteristics of 216 small objects were obtained from 63 students. Each object was rated on a scale (1 represented "low" and 9, "high") relative to the following stimulus dimensions: familiarity, complexity, utility, attractiveness, interest, and physical definition. A description of each of these dimensions is provided in Table 1.

Ratings of the objects on all dimensions were then submitted to multivariate normal mixture analysis (Wolfe, 1970) with the program NORMIX (Wolfe, 1965, 1967). Normal mixture analysis is a maximum-likelihood estimation for the parameters of multivariate normal distributions with unequal covariances. This

Table 1

Definitions of Evaluative Dimensions for Object Ratings

\begin{tabular}{ll}
\hline Familiarity & $\begin{array}{l}\text { How often this object has previously } \\
\text { been encountered. } \\
\text { Whether the object is simple, i.e., one- } \\
\text { dimensional, or complex, with many } \\
\text { angles and sides, etc. } \\
\text { The degree to which the object is seen to } \\
\text { be useful or has many common purposes. } \\
\text { The degree to which the object is appeal- } \\
\text { Utility }\end{array}$ \\
ing or attractive looking. \\
Attractiveness & $\begin{array}{l}\text { The degree to which the object seems } \\
\text { interesting as compared with being dull or } \\
\text { boring. } \\
\text { Thterest }\end{array}$ \\
The clarity of the structural components \\
of the objects; the degree to which corners \\
are sharply defined; the degree to which \\
the edges are clear and distinct.
\end{tabular}

Table 2

Means and Standard Deviations of Stimulus Object Ratings by Object Type

\begin{tabular}{lrrrrrrrr}
\hline & \multicolumn{2}{c}{ Type 1 } & & \multicolumn{2}{c}{ Type 2 } & & \multicolumn{2}{c}{ Type 3 } \\
\cline { 2 - 3 } \multicolumn{1}{c}{ Characteristic } & Mean & SD & & Mean & SD & & Mean & SD \\
\hline Familiarity & 6.43 & 1.69 & & 6.01 & 1.19 & & 3.65 & 1.18 \\
Complexity & 4.54 & 1.28 & & 5.85 & .84 & & 3.36 & .99 \\
Utility & 5.20 & 1.41 & & 2.74 & .56 & & 3.09 & .86 \\
Attractiveness & 3.84 & 1.11 & & 5.50 & 1.61 & & 2.71 & .97 \\
Interest & 3.92 & .98 & & 4.93 & 1.17 & & 2.73 & .66 \\
Physical Definition & 5.11 & .95 & & 5.22 & 1.36 & & 4.36 & .83 \\
\hline
\end{tabular}

Note $-1=$ low on the rated characteristic, and $9=$ high.

approach provided an objective means of classifying the objects into categories without any a priori assumptions about similarities or distances among the object ratings. The resulting categories of objects were based solely on ratings of stimulus characteristics. Any differences in memory for the different object groupings could then be confidently considered to be functions of rated stimulus characteristics.

Three categories of objects emerged as a result of the normal mixture analysis. Type 1 and Type 2 objects were generally rated moderately high (means $=6.43$ and 6.0 , respectively) for familiarity, whereas Type 3 objects were rated low on this dimension $($ mean $=3.65)$. Type 1 and Type 2 objects differed most appreciably in terms of utility (means $=5.20$ and 2.74 , respectively) and attractiveness (means $=3.84$ and 5.50 , respectively). Type 3 objects were rated markedly lower than Type 1 and Type 2 objects on most characteristics, with the single exception that Type 2 and Type 3 objects were rated similarly for utility. Mean ratings for the three categories of objects on all six stimulus dimensions are provided in Table 2 . Because no meaningful acronyms could be identified, the three groupings of items were referred to as Type 1 , Type 2, and Type 3 . Some examples of the objects used were: Type 1-a black rubber stopper, a sewing spool, a small plastic lemon, doll shoes, a small plastic flower, and a golf tee; Type 2-a small seashell, a blue foam pad, beads of varying sizes and shapes, and a star-shaped tinker toy; and Type 3-a green fuzzy ball, an oblong metal piece with a hole in the middle, a moon-shaped metal piece, and a plastic piece with threads inside. Many of the objects were pieces of larger objects and thus afforded no clear description. The objects varied greatly in shape, color, and identifiability. Redundancy of shape and color was avoided intentionally. All objects were small enough to fit onto a $5.08 \times 5.08 \mathrm{~cm}$ ( $2 \times 2$ in.) square.

Samples of 24 objects were selected randomly from each type of category to serve as target and distractor stimuli for the recognition study. Twelve objects from each group were placed randomly in three separate $40.64 \times 40.64 \mathrm{~cm}$ (16 x 16 in.) trays and designated as target objects. The remaining 12 objects from each group were mixed randomly with exact duplicates of the target objects, to make up a serial recognition test. The trays were provided with covers that could be removed for viewing. The test items also had individual covers so that they could be seen only when the cover was lifted.

\section{Procedure}

Week 1. The subjects participated individually. Each was asked to stand before a table on which were the three covered trays of target objects and was asked to "study each of the objects in each tray carefully for as long as the tray is open." The experimenter then removed the cover of each tray for $30 \mathrm{sec}$, one at a time. This allowed a viewing time of approximately $2.5 \mathrm{sec}$ per object (if all objects were viewed). The order of exposure to the trays was counterbalanced across subjects. 
Following the stimulus exposure, each individual was placed at a second table on which was a deck of playing cards. The subject was asked to arrange the cards by suit and kind. This distractor task was discontinued after $3 \mathrm{~min}$, at which time the recognition test was administered. The distractor task was included to ensure that the retention interval exceeded the normal short-term-memory duration.

The recognition test comprised 72 individual objects. Each test object was exposed for $5 \mathrm{sec}$. Half the objects were from the previous exposure sets, whereas the others were new. The subjects were instructed to mark "new" on a response sheet if the object had not been in the previously exposed arrays and "old" if it had been in the previous sets. The subjects rated their responses on a confidence scale $(1=$ not sure; $9=$ very sure).

Week 2. Each participant returned at the same hour 1 week later and completed the same recognition test. The subjects were then debriefed and dismissed.

\section{RESULTS}

The recognition data were transformed, according to signal-detectability theory, into d' scores (Swets, 1964) and analyzed in a two-factor ANOVA design with two within variables, retention interval and object type. Because the analysis and results of the confidence ratings were consistent with the recognition data, the means of both analyses are presented in Table 3 .

For recognition $\left(d^{\prime}\right)$, there were significant main effects for retention interval $[\mathrm{F}(1,23)=59.21, \mathrm{p}<.01]$ and for object type $[\mathrm{F}(2,46)=3.55, \mathrm{p}<.05]$. Recognition was higher for the initial test than for the test given 1 week later. Subsequent simple $F$ analyses indicated that Type 1 objects were better recognized than Type 3 objects $[\mathrm{F}(2,46)=5.28, \mathrm{p}<.05]$ but not Type 2 objects $(p>.05)$. Recognition for Type 2 objects did not differ from that for Type 1 or Type 3 objects. The interaction of retention interval (Week 1 to Week 2) and object type was not significant $(p>.05)$.

Analysis of confidence ratings also produced significant main effects of retention interval $[\mathrm{F}(1,23)=21.91$, $\mathrm{p}<.05]$ and object type $[\mathrm{F}(2,46)=7.18, \mathrm{p}<.05]$. Confidence declined over the retention interval. Subsequent simple $\mathrm{F}$ analyses indicated greater confidence for recognition of Type 2 than Type 3 objects $[F(2,46)$ $=16.04, p<.05]$. Confidence did not differ from Type 1 to Type 3 objects. The interaction among the two variables was not significant $(\mathrm{p}>.05)$.

Table 3

Means of Recognition ( $\left.d^{\prime}\right)$ and Confidence Scores by Retention Interval and Object Type

\begin{tabular}{cccccc}
\hline & \multicolumn{2}{c}{ Week 1 } & & \multicolumn{2}{c}{ Week 2 } \\
\cline { 2 - 3 } \cline { 5 - 6 } Object Type & $\mathrm{d}^{\prime}$ & Confidence & & $\mathrm{d}^{\prime}$ & Confidence \\
\hline Type 1 & 3.30 & 8.34 & & 2.06 & 7.39 \\
Type 2 & 2.97 & 8.55 & & 2.12 & 7.52 \\
Type 3 & 2.61 & 8.02 & & 1.87 & 7.07 \\
\hline
\end{tabular}

Note-1 = low on the confidence scale, and $9=$ high.

\section{DISCUSSION}

The expected decline in recognition performance after a 1 -week retention interval was confirmed. At initial testing, recognition performance was $89 \%$ accurate and declined to $80 \%$ after 1 week. This was consistent with the decline in confidence ratings over the test interval. The findings were similar to those reported by Shepard (1967) for pictorial stimuli. Although there was a significant decline over time, the indication was that recognition for common visual stimuli remains high over a 1-week period. Given the amount of visual interference that must occur over even a short period, this was surprising and attests to a stable visual schema.

The type of object, as defined by the evaluated informational characteristics of the objects, resulted in different levels of retention. This suggests that specific informational characteristics of the stimulus environment may exert an important influence on the retention of visual information. The results were the reverse of the prediction from verbal-learning literature. The observed pattern of recognition suggests that, for visual object recognition, less familiar objects (unlike unfamiliar words) apparently do not recieve the disproportionate boost in familiarity value provided by a single exposure. If familiarity is the main stumulus characteristic that determines recognition performance, memory and confidence ratings for Type 1 and Type 2 objects should have been inferior to those for Type 3 objects.

Further evidence for a different role of familiarity in object recognition from its role in word recognition derives from the realization that both Type 1 and Type 2 objects should have differed from Type 3 objects, since the familiarity ratings of Type 1 and 2 objects were quite similar. That Type 2 objects were not recognized differently from Type 3 is indicative of influence from other stimulus dimensions in the recognition process. Type 2 objects were rated lower in utility than were Type 1 objects. This suggests a potentially important role of perceived object usefulness involved in object recognition.

These findings suggest that schemata governing the organization and encoding of environmental information consist not only of familiarity information but also include other stimulus characteristics. The dimensions manipulated in the present study were not an exhaustive list of potentially influential stimulus information. To understand better the apparent multidimensional character of visual schemata, the influence of various stimulus attributes on memory must be considered.

\section{REFERENCES}

Bartlett, F. C. (1932). Remembering. Cambridge, England: Cambridge University Press.

Juola, J. F., Fischler, I., Wood, C. T., \& Atrinson, R. C. (1971). Recognition time for information stored in long-term memory. Perception \& Psychophysics, 10, 8-14.

KintsCH, W. (1967). Memory and decision aspects of recognition learning. Psychological Review, 74, 496-504.

KLATsky, R. L. (1980). Human memory: Structures and processes. San Francisco: Freeman.

MANDler, G. (1972). Organization and recognition. In E. Tulving \& W. Donaldson (Eds.), Organization of memory. New York: Academic Press.

MANDLER, G. (1980). Recognizing: The judgment of previous occurrence. Psychological Review, 87, 252-271.

Mandler, J. M., \& Johnson, N. S. (1977). Remembrance of things parsed: Story structure and recall. Cognitive Psychology, 9, 111-151.

Mandler, J. M., \& Parker, R. E. (1976). Memory for descriptive and spatial information in complex pictures. Journal of Experimental Psychology: Human Learning and Memory, 2, 38-48. 
Mandle R, J. M., \& Ritchey, G. H. (1977). Long term memory for pictures. Journal of Experimental Psychology: Human Learning and Memory, 3, 386-396.

Minsky, M. (1975). Frame-systems: A framework for representing knowledge. In P. H. Winston (Ed.), The psychology of computer vision. New York: McGraw-Hill.

Piaget, J., \& Inhelder, B. (1973). Memory and intelligence. New York: Basic Books.

SHEPARD, R. N. (1967). Recognition memory for words, sentences and pictures. Journal of Verbal Learning and Verbal Behavior, 6, 156-163.

Swets, J. A. (Ed.) (1964). Signal detection and recognition by human observers: Contemporary readings. New York: Wiley.

ThoRndike, E. L., \& LoRge, I. (1944). The teacher's word book of 30,000 words. New York: Teacher's College Press, Columbia University.

UNDE RWOOD, B. J. (1971). Recognition memory. In H. H. Kendler \& J. T. Spence (Eds.), Essays in neobehaviorism. New York: Appleton-Century-Crofts.
Underwood, B. J., \& Freund, J. S. (1970). Word frequency and short-term recognition memory. American Journal of Psychology, 83, 343-351.

Wolfe, J. H. (1965). A computer program for the maximumlikelihood analysis of types (Technical Bulletin No. 65-15). San Diego: U.S. Naval Personnel Research Activity. (Defense Documentation Center AD 620026)

WolfE, J. H. (1967). NORMIX: Computational methods for estimating the parameters of multivariate normal mixtures of distributions (Research Memorandum No. SRM 68-2). San Diego: U.S. Naval Personnel Research Activity. (Defense Documentation Center AD 656588)

Wolfe, J. H. (1970). Pattern clustering by multivariate mixture analysis. Multivariate Behavioral Research, 5, 329-350.

(Manuscript received for publication November 21, 1983.) 